$\mathrm{DE}$

M E D I C I N A

T R O P I C A L

$\mathrm{DE}$

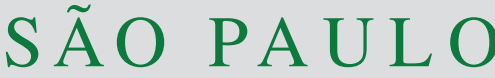

JOURNAL OF THE SÃO PAULO INSTITUTE OF TROPICAL MEDICINE

1Universidade Federal do Paraná, Departamento de Patologia Básica,

Curitiba, Paraná, Brazil

2Universidade Federal do Paraná, Departamento de Patologia Básica, Programa de Pós-Graduação em Microbiologia, Parasitologia e Patologia, Curitiba, Paraná, Brazi

${ }^{3}$ Universidade Federal Fluminense, Instituto Biomédico, Programa de Pós-Graduação em Microbiologia e Parasitologia Aplicada, Niterói, Rio de Janeiro, Brazil

${ }^{4}$ Universitat de València, Facultat de Farmàcia, Departamento de Farmàcia i Tecnologia Farmacèutica i Parasitologia, València, Spain

Correspondence to: Débora do Rocio Klisiowicz

Universidade Federal do Paraná, Departamento de Patologia Básica, Caixa Postal 19031, CEP 81531-980, Curitiba, PR, Brazil

Tel: +55 41 3361-1704, +55 41 3266-2042

E-mail: deborak@ufpr.br

Received: 26 August 2019

Accepted: 17 December 2019

\section{Vaccuuming method as a successful strategy in the diagnosis of active infestation by Pediculus humanus capitis}

Bruno Paulo Rodrigues Lustosa1, Juciliane Haidamak², Camila Yumi Oishi², Ariela Both de Souza ${ }^{1,3}$, Bruna Jacomel Favoreto de Souza Lima ${ }^{\circledR 2}$, Larissa Reifur ${ }^{1}$, Márcia Kiyoe Shimada1, Vânia Aparecida Vicente ${ }^{(1,2}$, Maria Adela Valero Aleixandre ${ }^{(1)}$, Débora do Rocio Klisiowicz ${ }^{(1,2}$

\section{ABSTRACT}

Most human epidemiological and clinical studies use visual inspection of the hair and scalp to diagnose Pediculus humanus capitis, however this method has low sensitivity to diagnose active infestations (presence of nymphs and adult lice). Vacuuming the hair and scalp has been used as a diagnostic method, but there are no previous data comparing its effectiveness with visual inspection. The aim of this study was to determine the prevalence of overall infestation (nits and trophic stages), of active infestation by Pediculus humanus capitis, and to evaluate the effectiveness of vacuuming in comparison with the visual inspection. Visual inspection was performed by three examiners and vacuuming of the scalp by one investigator, with an adapted vacuum cleaner. A total of 166 children aged 4 to 10 years old were randomly selected from public schools in Southern Brazil. Considering the positive results obtained by both methods, the prevalence of overall infestation was $63.3 \%$, whereas active infestation was $18.7 \%$. The visual inspection was more effective on diagnosing overall infestation, however, its effectiveness to detect active infestation was lower, ranging from $0.6 \%(\mathrm{RR}=3 \%, \mathrm{p}<0.001)$ to $6.6 \%(\mathrm{RR}=35 \%, \mathrm{p}=0.001)$, depending on the number of examiners. The effectiveness of vacuuming to diagnose active infestation was higher than the one of visual inspection, with a prevalence rate of $16.3 \%$ ( $R R=87 \%$, $\mathrm{p}=0.332$ ). As presented in our study, the vacuuming method was 2.74 to 7.87 times most likely to detect active infestation, thus it could be adopted as a more accurate method to diagnose active pediculosis.

KEYWORDS: Detection. Diagnosis. Effectiveness. Hair aspiration. Head lice. Pediculosis. Pediculus humanus capitis. Prevalence. Visual inspection.

\section{INTRODUCTION}

Pediculosis is a disease caused by the ectoparasite Pediculus humanus capitis (Phthiraptera: Pediculidae), known as head lice ${ }^{1}$. This parasite is an obligate bloodsucking arthropod detected on 30\% to 50\% of schoolchildren in Latin America ${ }^{2,3}$. The most common symptom of pediculosis is head pruritus, however, anemia, insomnia, secondary infection may occur, as well some dermatitis caused by longstanding cases. Despite these, many low intensity infestations remain asymptomatic $c^{4,5}$.

Most of the epidemiological and clinical studies in Latin America use the visual inspection procedure to diagnose head lice infestation ${ }^{2,6-9}$. However, this method has shown low accuracy to detect trophic stages, like nymphs and adult lice, especially in low intensity infestations ${ }^{4,5}$. Since a true positive result is determined by active 
pediculosis, which is acknowledged by the presence of trophic stages, many children are misdiagnosed by this method $^{5,10,11}$.

Other methodologies have been tested to improve the finding of active infestations, such as the combination with plastic or metal teeth head-lice comb ${ }^{11-13}$, a self-report diagnosis with standardized questionnaire ${ }^{14,15}$, and the use of an vacuuming apparatus to remove the head lice more easily $^{16,17}$. The vacuum apparatus was used in a previous survey, but its efficacy was not tested ${ }^{17}$.

Therefore, the aim of this study was to evaluate the effectiveness of the vacuuming apparatus, in addition to determining the prevalence of overall pediculosis (presence of nits and trophic stages) and active pediculosis in children from cities around Curitiba, Parana State, Southern Brazil.

\section{MATERIALS AND METHODS}

\section{Ethical standards}

This study was performed in accordance with the ethical standards of the 1964 Helsiki Declaration and with the Resolution 466/2012 from the National Health Council on Ethics in Research with human beings. The study was also approved by the Research Ethics Committee of the Federal University of Parana, under registration $\mathrm{N}^{\circ} \mathrm{CAAE}$ 38757614.9.0000.0102. A written informed consent was obtained from all the participants involved in the study and their legal guardians.

The study was conducted in two cities from the metropolitan area of Curitiba, Parana State, Southern Brazil: Almirante Tamandare (25'19'09"S 49 $18^{\circ} 14^{\prime \prime} \mathrm{W}$ ) and Lapa ( $\left.25^{\circ} 45^{\prime} 52^{\prime \prime} \mathrm{S} 49^{\circ} 43^{\prime} 20^{\prime \prime} \mathrm{W}\right)$. Both cities have relatively low income and medium human development index (HDI), around $0.700^{18}$. The children included in the study were 4 to 10 years old, and they studied in schools pre-selected by the educational municipal offices, based on the presence of reported pediculosis in the schools and the principal's acceptance to participate in the study.

\section{Diagnosis of pediculosis}

To determine the existence of pediculosis infestation, each child was examined by two distinct methods. The first method was an adapted visual inspection ${ }^{11}$. The hair of each child was divided into four quadrants: neck, behind the ears and top of the head. The duration of the inspection (visual inspection without the aid of instruments) varied according to the hair length, lasting around 3 to $5 \mathrm{~min}$. To improve the accuracy of this method, all of the children were inspected by three different examiners that were unaware of each other's results. After the three visual examinations, each child had their head inspected by a different investigator, through a vacuuming apparatus (Figure 1). This consisted of a regular vacuum cleaner $\left(\mathrm{LAVOR}^{\odot} 1400 \mathrm{~W}\right)$ adapted with a commercial voile used as a filter, inserted between the hose and the flat nozzle, to capture small particles and head lice (Figure 1). The vacuuming method was performed all over the child's head for 2 to $3 \mathrm{~min}$, according to the hair length, mostly on the neck and behind the ears. After vacuuming, the filter was removed and transferred to a $47 \mathrm{~mm}$ Petri dish to be analyzed with a stereomicroscope under 20-40 x magnifications.

To estimulate the voluntary participation, a "beauty salon" and a playful activity named "Power Machine" were used during the diagnostic procedure (Figure 1). The "Power machine" activity consisted of parting stickers to the vacuum cleaner and, at the beginning of the procedure, the child would select and touch her favorite sticker to "gain the power" of the chosen character, than the vacuum cleaner would "pass this power" to the child while the procedure was being conducted.

The diagnosis was performed by an expert medical entomologist, based on previously published references ${ }^{19-21}$, and the samples were classified as overall positive when any developmental stages from P. humanus capitis was detect, such as: nits, nymphs, adult, or any part of entomological evidence (hooks lice, antenna, lice molt or nits residuals $)^{11,22}$. In turn, a child was considered with active infestation when a trophic stage such as nymph or adult lice was detected; the presence of nits alone was not considered as active infestation ${ }^{11}$.

At the end of the study, all the participants diagnosed as positive for head lice infestation (active or overall) were referred to a health care unit. Following the diagnostic procedures, our group offered educational activities on head lice, including control measures, as part of an Extension program. Each family member received a folder with instructions regarding head lice biology and its prophylaxis, enabling the community empowerment.

\section{Statistical analysis}

Data analysis was performed by SigmaStat 3.5 program and BioEstat 5.0 program $^{23}$. Effectiveness was obtained by the Relative Risk test (RR) and significant values were analyzed by the $\chi^{2}$ test with $95 \%$ confidence interval. Odds Ratios were calculated to analyze the diagnosis likelihood of each method. Analysis of variance (ANOVA) was performed for comparisons among the examiners and the Student-Newman-Keuls post-test for multiple comparisons. 

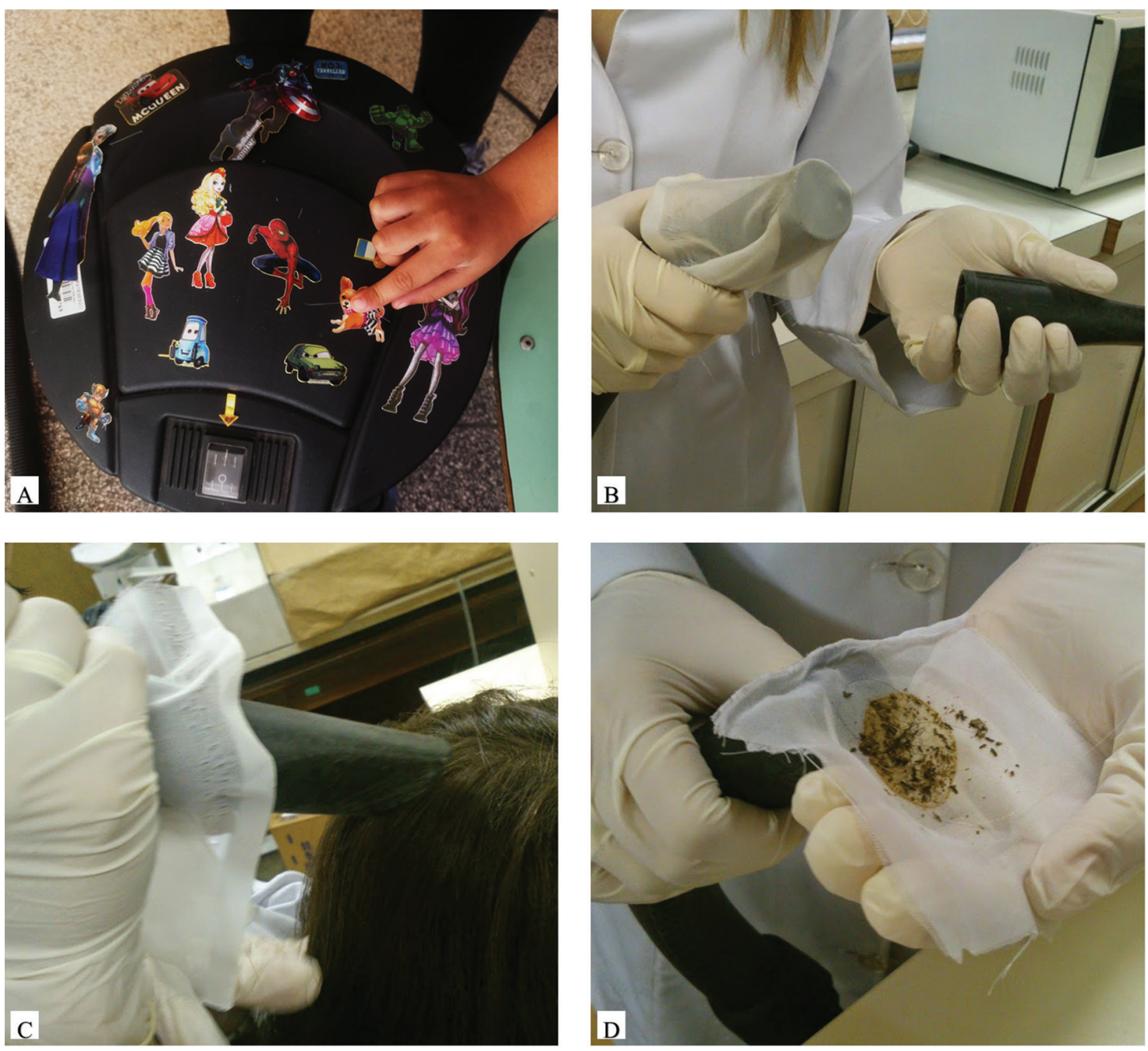

Figure 1 - Vacuuming method to diagnose pediculosis: A) the vacuum apparatus ("Power Machine") with the stickers characters to be chosen by the child; B) the voile inserted between the hose and the flat nozzle to capture head lice; C) vacuuming the head scalp; D) the voile after the vacuuming procedure.

\section{RESULTS}

The survey was conducted in 166 schoolchildren, aged 4 to 10 years old, 74 girls $(44.6 \%)$ and 92 boys $(55.4 \%)$. The overall prevalence of pediculosis was $63.3 \%$, while the prevalence of active infestation was $18.7 \%$ (Table 1). There was no statistical difference regarding sex or the comparison of the two cities (Table 1). Despite not reaching a statistical significance, according to the Odds Ratios, girls overall prevalence was 1.13 times higher than the one of the boys (64.9\% versus $62.0 \%$, respectively; $\chi^{2}=0.050, p=0.8225$ ). On the other hand, when looking at active infestation only, girls were 0.88 times more infested than boys ( $17.6 \%$ versus $\left.19.6 \% ; \chi^{2}=0.762, \mathrm{p}=0.743\right)($ Table 1$)$.

Through visual inspection, the overall prevalence of pediculosis estimated by each examiner varied from $36.7 \%$ to $47.6 \%$ (Table 2), with no statistical difference among them $(\mathrm{H}=4.378, \mathrm{p}=0.112)$. Nonetheless, there was a significant difference when more than one examiner inspected the child's head $(\mathrm{H}=33.487, \mathrm{p}<0.001)$ as the prevalence of overall infestation increased to $52.4 \%-62.7 \%$ when two or three examiners inspected the same child (Table 2). There was not any difference between two and three examiners $(\mathrm{H}=5.134, \mathrm{p}=0.148)$.

Considering the visual inspection method, a smaller number of children was diagnosed with active infestation, in comparison with the vacuuming method, and independently of the number of examiners. The prevalence of active pediculosis obtained by each examiner varied significantly from $0.6 \%$ to $4.8 \%(H=6.647, p=0.036)$ (Table 2). When more than one examiner inspected the child's head, the prevalence of active infestation was statistically higher in comparison with the inspection made by one examiner $(\mathrm{H}=14.836, \mathrm{p}=0.022)$ with rates of $2.4 \%$ to $6.6 \%$ (Table 2$)$. Moreover, there was no difference in the prevalence when two and three examiners diagnosed active infestations. 
Table 1 - Prevalence of overall and active pediculosis in schoolchildren from the Metropolitan Area of Curitiba according to the municipality and the gender.

\begin{tabular}{|c|c|c|c|c|c|c|c|c|c|}
\hline & \multirow{2}{*}{$\mathrm{N}$} & \multicolumn{4}{|c|}{ Overall pediculosis } & \multicolumn{4}{|c|}{ Active pediculosis } \\
\hline & & $\mathrm{N}^{\mathrm{ov}}$ & $\%$ & OR & $p$-value & $\mathrm{N}^{\mathrm{ac}}$ & $\%$ & OR & $p$-value \\
\hline \multicolumn{10}{|l|}{ City } \\
\hline Lapa & 91 & 61 & 67.0 & 1.433 & 0.341 & 14 & 15.4 & 0.620 & 0.318 \\
\hline Almirante Tamandare & 75 & 44 & 58.7 & & & 17 & 22.7 & & \\
\hline \multicolumn{10}{|l|}{ Sex } \\
\hline Girl & 74 & 48 & 64.9 & 1.134 & 0.823 & 13 & 17.6 & 0.876 & 0.743 \\
\hline Boy & 92 & 57 & 62.0 & & & 18 & 19.6 & & \\
\hline Total & 166 & 105 & 63.3 & & & 31 & 18.7 & & \\
\hline
\end{tabular}

$\mathrm{N}=$ Number of participants; $\mathrm{N}^{\mathrm{ov}}=$ Number of children with overall pediculosis; $\mathrm{N}^{\mathrm{ac}}=$ Number of children with active pediulosis; $\%=$ prevalence of positive results; OR = Odds Ratio test result; $p$-value = significant values when $p<0.05$

Table 2 - Effectiveness of visual inspection and vacuuming methods for diagnosing pediculosis and active pediculosis in schoolchildren from the Metropolitan Area of Curitiba.

\begin{tabular}{|c|c|c|c|c|c|c|c|c|}
\hline \multirow{2}{*}{ Method } & \multicolumn{4}{|c|}{ Overall pediculosis } & \multicolumn{4}{|c|}{ Active pediculosis } \\
\hline & Positive & $\%$ & $\mathrm{RR}$ & $p$-value & Positive & $\%$ & $\mathrm{RR}$ & $p$-value \\
\hline Examiner 1 & 75 & 45.2 & 0.71 & $<0.05$ & 1 & 0.6 & 0.03 & $<0.05$ \\
\hline Examiner 2 & 79 & 47.6 & 0.75 & $<0.05$ & 3 & 1.8 & 0.10 & $<0.05$ \\
\hline Examiner 3 & 61 & 36.7 & 0.58 & $<0.05$ & 8 & 4.8 & 0.26 & $<0.05$ \\
\hline Examiners1 \& 2 & 102 & 61.4 & 0.97 & $0.410^{\star}$ & 4 & 2.4 & 0.13 & $<0.05$ \\
\hline Examiners $1 \& 3$ & 90 & 54.2 & 0.86 & $0.059^{\star}$ & 8 & 4.8 & 0.26 & $<0.05$ \\
\hline Examiners $2 \& 3$ & 87 & 52.4 & 0.83 & $<0.05$ & 11 & 6.6 & 0.35 & $<0.05$ \\
\hline Examiners 1, 2 \& 3 & 104 & 62.7 & 0.99 & $0.500^{*}$ & 11 & 6.6 & 0.35 & $<0.05$ \\
\hline Vacuuming & 51 & 30.7 & 0.49 & $<0.05$ & 27 & 16.3 & 0.87 & $0.332^{*}$ \\
\hline Total & 105 & 63.3 & & & 31 & 18.7 & & \\
\hline
\end{tabular}

Number of participants = 166; Positive = number of positive results diagnosed by each method; \% = prevalence of positive results; $\mathrm{RR}=$ Relative Risk test of being diagnosed by each method; $p$-value = significant values considered when $p<0.05 ;{ }^{*} p$-values considered statistically non-different from the total.

Through the vacuuming method, $30.7 \%$ of the children had positive results for overall infestation and $16.3 \%$ for active infestation. Considering that by visual inspection, the highest prevalence for overall infestation was $62.7 \%$, the visual inspection was more sensitive in detecting overall pediculosis (Table 2 and 3). Nonetheless, vacuuming was the most reliable method to diagnose active infestation, when compared to the visual inspection in all active pediculosis cases $(\mathrm{RR}=87 \%, \mathrm{p}=0.332$, Table 2 ).

Visual inspection, with two up to three examiners, was the most effective method to diagnose overall pediculosis $(\mathrm{H}=58.465, \mathrm{p}<0.001)$. Odds Ratios showed that the visual inspection was 2.87 (two viewers) to 3.78 (three viewers) times better than vacuuming (Table 3 ). In contrast, vacuuming was more effective in detecting active infestation $(\mathrm{H}=58.465, \mathrm{p}<0.001)$. The Odds Ratios showed that this method is 2.74 times better in detecting trophic stages than three examiners diagnosis by visual inspection (Table 4). Even though, four children diagnosed with active infestation by visual inspection were not detected by vacuuming (Table 2).

\section{DISCUSSION}

The present study is the first to report the pediculosis prevalence in Southern Brazil. The $63.3 \%$ overall pediculosis prevalence detected by the present study (Table 1), was much higher than the national average of $24 \%{ }^{2}$. This is one of the highest pediculosis prevalence described in the American continent, together with those obtained by combing and visual inspections in Argentina's endemic areas $(85 \% \text { and } 69 \%)^{24,25}$. Taking into consideration the active pediculosis prevalence, the $18.7 \%$ obtained in this study (Table 1) was also one of the highest 
Table 3 - Statistical analyses (OR and $p$-value) showing the likelihood of the visual inspection overcoming the vacuuming regarding the overall pediculosis diagnosis.

\begin{tabular}{|c|c|c|c|c|c|c|}
\hline \multirow{2}{*}{ Method } & \multicolumn{2}{|c|}{1 examiner rate } & \multicolumn{2}{|c|}{2 examiners rate } & \multicolumn{2}{|c|}{3 examieners rate } \\
\hline & OR & $p$-value & OR & $p$-value & OR & $p$-value \\
\hline \multicolumn{7}{|l|}{1 examiner } \\
\hline 2 examiners & 1.663 & 0.028 & & & & \\
\hline 3 examiners & 2.190 & 0.001 & 1.317 & 0.264 & & \\
\hline Vacuuming & 1.727 & 0.023 & 2.874 & $<0.001$ & 3.782 & $<0.001$ \\
\hline
\end{tabular}

1 examiner rate $=$ rate of positive results obtained by one examiner only; 2 examiners rate $=$ rate of positive results obtained by two examiners; 3 examiners = positive results obtained by three examiners; OR = Odds ratio test result; $p$-value = significant values considered when $\mathrm{p}<0.05$

Table 4 - Statistical analyses (OR and $p$-value) showing the likelihood of vacuuming overcoming the visual inspection for active pediculosis diagnosis.

\begin{tabular}{|c|c|c|c|c|c|c|}
\hline \multirow{2}{*}{ Method } & \multicolumn{2}{|c|}{1 examiner rate rate } & \multicolumn{2}{|c|}{2 examiners rate rate } & \multicolumn{2}{|c|}{3 examiners rate } \\
\hline & OR & $p$-value & OR & $p$-value & OR & $p$-value \\
\hline \multicolumn{7}{|l|}{1 examiner } \\
\hline 2 examiners & 2.051 & 0.378 & & & & \\
\hline 3 examiners & 2.874 & 0.113 & 1.402 & 0.637 & & \\
\hline Vacuuming & 7.867 & $<0.001$ & 3.836 & 0.001 & 2.737 & 0.010 \\
\hline
\end{tabular}

1 examiner rate $=$ rate of positive results obtained by one examiner only; 2 examiners rate $=$ rate of positive results obtained by two examiners; 3 examiners $=$ positive results obtained by three examiners; OR = Odds ratio test result; $p$-value $=$ significant values considered when $\mathrm{p}<0.05$

reported in the country ${ }^{26,27}$. Despite the fact that Curitiba city, Parana State capital is one of the most developed cities in the country, with a high HDI ( 0.8 to 1$)$; there are less developed municipalities in its surrounding ${ }^{18}$, like the cities included in this survey.

The comb method is 2 to 4 times faster and more effective to diagnose active pediculosis than the visual inspection method ${ }^{11,13,28}$, however, its acceptance can be low by children and parents who may complain about embarrassment, tedious, time-consuming and physical discomfort ${ }^{29}$. In the present study, we chose not to use the comb method because most children from the community have dense and curly hair and would complain about combing as being "painful" and an embarrassing procedure. Thus, we used another methodology, the vacuuming method, and added a playful activity ${ }^{30}$ to it, to increase the acceptance by children and the approval by their parents.

The prevalence of overall infestation in girls observed at the present study is similar to the reported ones in other studies from Brazil and other countries ${ }^{9,17,31}$. The differences between sex may be associated to behavioral variations ${ }^{6}$. However, this behavioral variation may not be considered when taking into consideration the active infestation, as in the present study there was not a statistical difference between the prevalence of active infestation in boys and girls (Table 1). Considering that the empty nit can remain attached to the hair as long as six months after the infestation ${ }^{4}$, the finding of an empty nit could result in a false positive for head lice infestation, mainly in children with long hair ${ }^{10,19,25}$. Considering that, this difference may be more related to hair length than to sex ratio ${ }^{6,9}$.

In the present study, it was observed that at least two examiners are optimal to validate the diagnosis by the visual inspection method (Table 3). Considering the Odds Ratio test, two examiners are 1.66 times more likely to detect overall infestation in schoolchildren than only one examiner $(\mathrm{p}=0.028$, Table 3$)$. However, when only active infestation was considered, this difference was not significant ( $p=0.378$, Table 4$)$. The diagnosis conducted by two examiners has already being reported, however these studies did not measure the agreement between the examiners ${ }^{8,13,19}$. Nonetheless, in the present study, the effectiveness of visual inspection in detecting active infestation did not surpass $40 \%$ considering all the positive cases ( $R R=35 \%$, Table 2 ), which was similar to other studies ${ }^{11,15}$. The number of positive cases for active infestation is lower because trophic stages can avoid light and use camouflage, making it hard to identify them on the head by visual inspection ${ }^{19,28,32}$. 
Visual inspection seems to be the method of choice in Brazilian researches as most of the previously published work used it to detect active pediculosis ${ }^{15,26,27}$. However, even if the result is obtained by different examiners, this method usually overestimate the number of positive cases, as the examiners consider empty nits as an indicative of active infestation, and they often fail to distinguish between active and past infestation ${ }^{10-12,28}$. Thus, the children diagnosed as positive by the visual inspection may be treated unnecessarily, missing school days, and their parents missing working days 3 ,10,13,19.

Several reports show that a lack of basic knowledge and many myths regarding pediculosis are frequent among school communities $^{33-35}$. The major problem pointed by these reports was the misunderstanding on how head lice are transmitted and treated. Another concern is the embarrassment among parents of infested children, which interfere with the management of this medical condition ${ }^{29}$. There is not a public program directed to the control of head lice in both regions studied, thus the creation of permanent educational programs, associated with the correct diagnosis, may help to reduce the prevalence of active pediculosis in schoolchildren ${ }^{9,34,35}$.

This was the first study comparing vacuuming with visual inspection in the diagnosis of head lice. In the present study, the prevalence of active pediculosis obtained by vacuuming was significantly higher $(\mathrm{RR}=87 \%$, Table 2$)$ than visual inspection. Other studies have described that the vacuum cleaner is efficient to remove head lice from carpets and fomites ${ }^{16}$, and it has been already used to detect active pediculosis in schoolchildren, but vacuuming was not compared to other methods ${ }^{17}$.

Our results show that vacuuming was the best method to detect active pediculosis (Table 4). However, four children diagnosed with living lice, by visual inspection, were not diagnosed as positive by the vacuuming (Table 2). This could have occurred because the visual inspection (with removal of the living louse, owing to ethical reasons) was conducted prior to the vacuuming exam or due to mishandling by the researcher that performed the vacuum method. Thus, if the head lice were not removed during the visual inspection, those children would probably have been properly diagnosed by the vacuuming.

There is no previously published data comparing the vacuuming and the visual inspection methods. The vacuuming showed to be 7.87 times better to detect active infestation than the visual inspection made by one examiner $(\mathrm{p}<0.001$, Table 4$)$. There is not a study comparing the comb method with the vacuuming method to diagnose active pediculosis, so that new studies are necessary to determine what methodology is the most effective. As the effectiveness of the vacuuming method and its acceptance associated with the playful activity was high, it could be used by educational and health offices as the standard method to diagnose active pediculosis, to improve public health and to reduce the prevalence of active pediculosis in schoolchildren.

\section{ACKNOWLEDGMENTS}

We thank the undergraduate students Valéria Mendes Soares, Raquel Vizzotto de Menezes, Raymundo Seguí López-Peñalver and Lourdes Mengual Sanches and the laboratory assistant Eliana Maura Leite, for their assistance during the diagnostic procedures and their collaboration with the Extension program and educational activities.

\section{AUTHORS' CONTRIBUTIONS}

JH, CYO, VAV and DRK contributed to the study conception and design; JH, CYO, ABS and BJFSL attended the patients, applied the questionnaire and obtained the data and the informed consent from the patients and their legal guardians; JH, CYO and DRK performed the lab experiments; BPRL, LR, MKS, MAV and DRK analyzed the data and wrote the manuscript. All of the authors have read the paper and approved the final version.

\section{CONFLICT OF INTERESTS}

The authors state that they have no conflict of interest to declare.

\section{FINANCIAL SUPPORT}

This research was funded by UFPR Office for Extension and Culture (PROEC) and by the Brazilian Extension Program for Universities (ProExt). Scholarship from UFPRTesouro Nacional and Araucária Foundation (to Lustosa BPR), CAPES (to Haidamak J, Oishi CY, Souza AB and Lima BJFS), and National Counsel of Technological and Scientific Development, Brasilia, Brazil, for fellowship (Vicente VA).

\section{REFERENCES}

1. De Geer C. Mémories pour servir à l'historie naturelle des insectes. Stockholm: Pierre Hesselberg; 1778. p.69-82.

2. Devera R. Epidemiología de la pediculosis capitis en América Latina. Saber. 2012;24:25-36.

3. Amazonas PH, Souza RB, Mendes J, Moroni FT, Borges-Moroni R. Pediculose em crianças e jovens atendidos em orfanatos e ambulatório público de Manaus, AM, Brasil. Rev Patol Trop. 2015;44:207-14.

4. Nutanson I, Steen CJ, Schwartz RA, Janniger CK. Pediculus 
humanus capitis: an update. Acta Dermatovenerol Alp Pannonica Adriat. 2008;17:147-59.

5. Cummings C, Finlay JC, MacDonald NE. Les infestations par les poux de tête: une mise à jour clinique. Paediatr Child Health. 2018;23:e25-e32.

6. Borges R, Mendes J. Epidemiological aspects of head lice in children attending day care centers, urban and rural schools in Uberlandia, central Brazil. Mem Inst Oswaldo Cruz. 2002;97:189-92.

7. Catalá S, Carrizo L, Córdoba M, Khairallah R, Moschella F, Bocca JN, et al. Prevalência e intensidade da infestação por Pediculus humanus capitis em escolares de seis a onze anos. Rev Soc Bras Med Trop. 2004;37:499-501.

8. Heukelbach J, Walton SF, Feldmeier H. Ectoparasitic infestations. Curr Infect Dis Rep. 2005;7:373-80.

9. Mendes GG, Borges-Moroni R, Moroni FT, Mendes J. Head lice in school children in Uberlândia, Minas Gerais State, Brazil. Rev Patol Trop. 2017;46:200-8.

10. Pollack RJ, Kiszewski AE, Spielman A. Overdiagnosis and consequent mismanagement of head louse infestations in North America. Pediatr Infect Dis J. 2000;19:689-93.

11. Jahnke C, Bauer E, Hengge UR, Feldmeier H. Accuracy of diagnosis of pediculosis capitis: visual inspection vs wet combing. Arch Dermatol. 2009;145:309-13.

12. Balcioglu C, Burgess IF, Limoncu ME, Şahin MT, Ozbel Y, Bilaç $\mathrm{C}$, et al. Plastic detection comb better than visual screening for diagnosis of head louse infestation. Epidemiol Infect. 2008;136:1425-31.

13. De Maeseneer J, Blokland I, Willems S, Vander Stichele RV, Meersschaut F. Wet combing versus traditional scalp inspection to detect head lice in schoolchildren: observational study. BMJ. 2000;321:1187-8.

14. Linardi PM, Maria M, Botelho JR, Cunha HC, Ferreira JB. Pediculose capitis: prevalência em escolares da rede municipal pública de Belo Horizonte, Minas Gerais, Brasil. Mem Inst Oswaldo Cruz. 1989;84 Suppl 4:327-31.

15. Pilger D, Khakban A, Heukelbach J, Feldmeier H. Selfdiagnosis of active head lice infestation by individuals from an impoverished community: high sensitivity and specificity. Rev Inst Med Trop Sao Paulo. 2008;50:121-2.

16. Takano-Lee M, Edman JD, Mullens BA, Clark JM. Transmission potential of the human head louse, Pediculus capitis (Anoplura: Pediculidae). Int J Dermatol. 2005;44:811-6.

17. Birkemoe T, Lindstedt HH, Ottesen P, Soleng A, Næss Ø, Rukke BA. Head lice predictors and infestation dynamics among primary school children in Norway. Fam Pract. 2015;33:23-9.

18. Programa das Nações Unidas para o Desenvolvimento. Atlas do desenvolvimento humano no Brasil: árvore do IDHM. [cited 2019 Dec 18] Available from: http://www.atlasbrasil.org. br/2013/pt/arvore/municipio/anicuns_go_2010/municipio/ penaforte_ce_2010/
19. Keilin D, Nuttall GH. Iconographic studies of Pediculus humanus. Parasitology. 1930;22:1-10.

20. Stojanovich CJ Jr. The head and mouthparts of the sucking lice (Insecta: Anoplura). Microentomology. 1945;10:1-46.

21. Soler Cruz M, Martin Mateo M. Scanning electron microscopy of legs of two species of sucking lice (Anoplura: Phthiraptera). Micron. 2009;40:401-8.

22. Williams LK, Reichert A, MacKenzie WR, Hightower AW, Blake PA. Lice, nits, and school policy. Pediatrics. 2001;107:1011-5.

23. Ayres M, Ayres Jr M, Ayres DL, Santos AA. BioEstat 5.0: aplicações estatísticas nas áreas das ciências biológicas e médicas. Belém; Sociedade Civil Mamirauá; 2007.

24. Chouela E, Abeldaño A, Cirigliano M, Ducard M, Neglia V, La Forgia M, et al. Head louse infestations: epidemiologic survey and treatment evaluation in Argentinean schoolchildren. Int $\mathbf{J}$ Dermatol. 1997;36:819-25.

25. Toloza AC, Laguna MF, Ortega-Insaurralde I, Vassena C, RisauGusman S. Insights about head lice transmission from field data and mathematical modeling. J Med Entomol. 2018;55:929-37.

26. Heukelbach J, Winter B, Wilcke T, Muehlen M, Albrecht S, Oliveira FA, et al. Selective mass treatment with ivermectin to control intestinal helminthiases and parasitic skin diseases in a severely affected population. Bull World Health Organ. 2004;82:563-71.

27. Rocha EF, Sakamoto FT, Silva MH, Gatti AV. Investigação da intensidade de parasitismo, prevalência e ação educativa para controle de pediculose. Perspect Med. 2012;23:5-10.

28. Mumcuoglu KY, Friger M, Ioffe-Uspensky I, Ben-Ishai F, Miller J. Louse comb versus direct visual examination for the diagnosis of head louse infestations. Pediatr Dermatol. 2001;18:9-12.

29. Gordon SC. Shared vulnerability: a theory of caring for children with persistent head lice. J Sch Nurs. 2007;23:283-92.

30. Coscrato G, Pina JC, Mello DF. Utilização de atividades lúdicas na educação em saúde: uma revisão integrativa da literatura. Acta Paul Enferm. 2010;23:257-63.

31. Moosazadeh M, Afshari M, Keianian H, Nezammahalleh A, Enayati AA. Prevalence of head lice infestation and its associated factors among primary school students in Iran: a systematic review and meta-analysis. Osong Public Health Res Perspect. 2015;6:346-56.

32. Frankowski BL, Bocchini JA. Head lice. Pediatrics. 2010;126:392403.

33. Magalhães KP, Silva JB. A infestação por pediculose e o ensino de saúde. Rev Saude Pesq. 2012;5:408-16.

34. Cunha PV, Pinto ZT, Liberal EF, Barbosa JV. O discurso dos professores sobre a transmissão da pediculose. Rev Bras Crescimento Desenvolv Hum. 2008;18:298-307.

35. Sangaletti V, Santos R, Bosa C, Klisiowicz DR. Percepção dos professores dos CMEIs da Matriz sobre a pediculose humana. Rev Teoria Prat Educ. 2018;18:9-14. 